\title{
"Prediction of Grade of Urothelial Carcinoma of Urinary Bladder from the Size and Number of Tumors at First Presentation"
}

\author{
Mahbubul Islam Khandoker', Md. Shamim Hossain², A.S.M Shafiul Azam³, Muhammad \\ Serajul Islam ${ }^{4}$, Akter Kamal Perveg ${ }^{5}$, Mohammad Abdus Salam ${ }^{6}$, A. K. Al-Miraj ${ }^{7}$ \\ ${ }^{I}$ Medical Officer, Department Of Urology, BSMMU, Dhaka. Bangladesh \\ ${ }^{2}$ Assistant Professor, Department Of Urology, BSMMU, Dhaka, Bangladesh \\ ${ }^{3}$ Consultant, Department Of Urology, BSMMU, Dhaka. Bangladesh \\ ${ }^{4}$ Medical Officer, Department of Urology, BSMMU, Dhaka, Bangladesh \\ ${ }^{5}$ Medical Officer, Department of Urology, BSMMU, Dhaka, Bangladesh \\ ${ }^{6}$ Founder President \& CEO, Urology And Transplant Foundation Of Bangladesh And Former Chairman \& \\ Professor Of Uro-Oncology, BSMMU, Dhaka, Bangladesh
}

${ }^{7}$ Research Assistant, Department of Vascular Surgery, BSMMU, Dhaka, Bangladesh

*Corresponding Author: Mahbubul Islam Khandoker, Medical officer, Department of Urology, BSMMU, Dhaka, Bangladesh.

\begin{abstract}
Background: Early diagnosis and prompt treatment can save lives of the patients with bladder cancer. The confirmatory test for grade of the disease is histopathological examination after transurethral resection. But if the grade of the tumor can be predicted at the time of presentation from size and number of tumors seen by ultrasonographic imaging, clinician can counsel the patient beforehand and also arrange rapid treatment to save life.
\end{abstract}

Objective: To assess the size and number of tumors as clinical predictors of histological grade of urothelial carcinoma of urinary bladder before first-time transurethral resection of the bladder tumor (TURBT).

Methods: This cross-sectional study was conducted in the Department of Urology, BSMMU and RGRH from January 2020 to April 2020. Fifty patients were enrolled in this study. Size and number of the tumor was determined by preoperative ultrasonography of urinary bladder. Histopathological examination was used to determine the grade of the tumor after TURBT. Statistical analysis was performed using SPSS version 22.0.

Results: Mean age of the study subjects was $52.04 \pm 18.37$ years within the range of 22-95 years. Males $(56.0 \%)$ were predominant than females (44.0\%). Male to female ratio was 1.27:1. Mean number of tumor was $1.28 \pm 0.64$ (1-3) and mean tumor size was $3.54 \pm 1.47 \mathrm{~cm}$ (1-7). High grade tumor was 26 (52.0\%) and low grade tumor was 24 (48.0\%). There was no significant association of tumor grading with number of tumor in this study. High grade tumor was significantly higher among the study subjects with tumor size $>3.5 \mathrm{~cm}$. Area under curve (AUC) of tumor number and tumor size was 0.558 and 0.827 respectively in prediction of tumor grading. Sensitivity, specificity, PPV, NPV and accuracy of tumor number (at cut of value 3) was 15.4\%, 95.8\%, $80.0 \%, 51.1 \%$ and $54.0 \%$ respectively. Sensitivity, specificity, PPV, NPV and accuracy of tumor size (at cut of value $3.5 \mathrm{~cm}$ ) was $90.5 \%, 76.3 \%, 80.9 \%, 87.9 \%$ and $83.7 \%$ respectively. Overall Sensitivity, specificity, PPV, NPV and accuracy of tumor size was better than tumor number in prediction of tumor grading.

Conclusion: According to this study finding, it can be concluded that the grade of newly diagnosed bladder tumors can be predicted with high accuracy using tumor size.

Keywords: TURBT, tumor size, number of tumor.

\section{INTRODUCTION}

Bladder cancer is the second most common cancer of the genito-urinary tract [1]. It is the $9^{\text {th }}$ most common cancer in the world [2], and is the $13^{\text {th }}$ most common cause of death accounting for 145,000 deaths worldwide [2, 3]. At initial 
diagnosis, more than $70 \%$ of patients have nonmuscle invasive bladder cancer (NMIBC), which is generally treated with (TURBT) with or without intravesical therapy [4]. Bladder carcinoma is highly diverse disease which can be low grade or high grade. Low grade tumors are recurrent but posses less threat to patient's life. But high grade tumors are potentially fatal as they are highly likely to invade the muscle coat $[5,6]$. Thus, high-grade is one of the most important factors for predicting a poor clinical outcome in NMIBC. The histological grade of the bladder cancer is eventually determined by examining the resected tumor under microscope after TURBT. The most widely used classification for grading of NMIBC (G1, G2 and G3) was the 1973 World Health Organization (WHO) classification [7]. However, a revised grading system for urothelial carcinoma (UC) (low-grade and high-grade) was proposed and adopted by the WHO in 2004 to replace the 1973 WHO classification system [8]. Urologists often clinically suspects broad based tumors as high grade and pedunculated tumors as low grade. But this is obscure and not greatly supported by data. Also clinicians usually suspects large and multiple tumors to be of high grade. But there is very sparse data to support this. This study is designed to assess the size and number tumor in the urinary bladder as clinical predictor of tumor grade even before histopathological examination. This will definitely help the clinicians to identify patients with potentially high-grade bladder carcinoma early in the clinical course and rapidly treat them to improve the clinical outcome.

\section{OBJECTIVES}

\section{General Objective:}

a) To assess the size and number of tumors as clinical predictors of histological grade of urothelial carcinoma of urinary bladder before first-time transurethral resection of the bladder tumor (TURBT).

\section{Specific Objective:}

a) To determine the size of bladder tumor by ultrasonography (USG).

b) To determine the number of tumors by USG.

c) To determine the grade of the tumor by histopathological examination after TURBT. d) To compare the size and number of tumor with histological grade.

\section{Methodology}

This cross-sectional study was conducted in the Department of Urology, BSMMU and RGRH from January 2020 to April 2020. Fifty patients were enrolled in this study. Size and number of the tumor was determined by preoperative ultrasonography of urinary bladder. Histopathological examination was used to determine the grade of the tumor after TURBT.

\section{Selection Criteria:}

\section{Inclusion criteria:}

- Patients with detectable bladder tumor by USG.

- No previous history of TURBT.

\section{Exclusion Criteria:}

- Patients with Recurrent bladder mass.

- Tumor grossly extending beyond urinary bladder.

Data processing and analysis: Data editing cleaning and reduction was done by taking care for omission and illegal entry of data. After compilation the data were presented in the form of tables and figures as necessary. Statistical analysis was performed using SPSS version 22.0. Quantitative data was tabulated as a mean \pm standard deviation and significance was analyzed by using independent sample $t$-test. Qualitative data was tabulated as frequency \& percentage and was compared with Chi-square test. Statistical significance will be set at $P<0.05$.

Ethical consideration: Participation of the respondents in the study was voluntary. Informed consent has been obtained after a brief overview of the study to all the respondents. It has been clarified to them that they have the liberty to refuse or take part in the study. All information will be kept confidential. The interview was conducted at suitable times and interview place which was convenient to the respondents. Due permission has been taken from the particular institution.

\section{Bladder Cancer}

Epidemiology of $\boldsymbol{B C}$ : $\mathrm{BC}$ is the most common malignancy of the urinary tract, the 7 th most common cancer in men and the 17th in women [9]. The worldwide age-standardized incidence rate is 9 per 100,000 for men and 2 
per 100,000 for women (2008 data) [10]. In the European Union (EU), the age-standardized incidence rate is 27 per 100,000 for men and 6 per 100,000 for women [12]. The incidence of BC varies between regions and countries; in Europe, the highest age-standardized incidence rate has been reported in Spain (41.5 in men and 4.8 in women) and the lowest in Finland (18.1 in men and 4.3 in women) [10]. Worldwide agestandardized mortality rate is 3 for men versus 1 per 100,000 for women. In the EU, the age standardized mortality rate is 8 for men and 3 per 100,000 for women, respectively [12]. In 2008, BC was the eighth most common cause of cancer-specific mortality in Europe [10]. The incidence of $\mathrm{BC}$ has decreased in some areas, possibly reflecting the decreased impact of causing agents, mainly smoking and occupational exposure [13]. Mortality from BC has also decreased, possibly reflecting an increased standard of care [11].

Etiology of BC: Tobacco smoking is the most important risk factor for $\mathrm{BC}$, accounting for approximately $50 \%$ of the cases, $[14,15]$, because tobacco smoke contains aromatic amines and polycyclic aromatic hydrocarbons, which are renally excreted. Cigarette smokers have a twoto fourfold increased risk of bladder cancer compared with non-smokers [16], and the risk increases with increasing intensity and duration of smoking [20]. On cessation of smoking, the risk of bladder cancer falls $>30 \%$ after $1-4$ years and by $>60 \%$ after 25 years but never returns to the risk level of non-smokers [12]. Occupational exposure to aromatic amines, polycyclic aromatic hydrocarbons, and chlorinated hydrocarbons is the second most important risk factor for BC, accounting for about $10 \%$ of all cases. This type of occupational exposure occurs mainly in industrial plants processing paint, dye, metal, and petroleum products $[17,18]$. Although the significance of the amount of fluid intake is uncertain, the chlorination of drinking water and subsequent levels of trihalomethanes are potentially carcinogenic, while exposure to arsenic in drinking water increases the risk [14]. The association between personal hair dye use and risk remains uncertain; an increased risk has been suggested in users of permanent hair dyes with an NAT2 slow acetylation phenotype $[19,20]$. The impact of diet and environmental pollution is less evident. Exposure to ionizing radiation is connected with increased risk. It is suggested that cyclophosphamide and pioglitazone are weakly associated with $\mathrm{BC}$ risk
[14]. Schistosomiasis, a chronic endemic cystitis, based on recurrent infection with a parasitic trematode, is a cause of BC [14]. Finally, there is increased evidence that genetic predisposition may influence the incidence of TCC of the bladder [14], especially via its impact on susceptibility to other risk factors [14,21].

Prognostic Factors (PF) of NMIBC: NMIBC is a heterogeneous group of tumors whose prognosis and therapeutic indications are very difficult to establish at the diagnosis time. Although TURBT is an essential diagnostic tool and an effective treatment for bladder cancer, $45 \%$ of patients will have tumor recurrence within 12 months of TURBT alone. Tumor recurrence can be attributed to a combination of missed tumors, incomplete, initial resection, reimplantation of tumor cells after resection, and tumor occurrence in high risk urothelium. Several factors influence the recurrence rate, for instance, clinical and pathological results, applied treatments, and diagnostics. There are two fundamental risks attributed to NMIBC: the risk of recurrence without worsening the grade or stage and the risk of progression to MIBC. So, according to this behavior, basically, NMIBC can be classified into three groups of patients. A minority of patients $(20-30 \%)$ have a relatively benign type of TCC with a low recurrence rate. These low risk tumors do not show progression. The largest group of patients includes those who frequently develop a NMIBC recurrence but seldom experience progression. A third, small group of patients, includes those who have a relatively aggressive non-muscle invasive tumor at presentation. Despite maximum treatment, up to $45 \%$ of these patients will develop MIBC. The desire to predict which NMIBC will become MIBC and will develop disseminated disease has stimulated the study of factors with possible prognostic value; these are called prognostic factors $(\mathrm{PF})$.

\section{RESUlts}

Mean age of the study subjects was $52.04 \pm 18.37$ years within the range of $22-95$ years. Maximum patients were $>60$ years followed by $51-60$ years $(24.0 \%), 21-30$ years $(18.0 \%), 31$ 40 years $(16.0 \%)$ and $41-50$ years $(14.0 \%)$.

Table1. Distribution of the study subjects according to age $(N=50)$

\begin{tabular}{|l|l|l|}
\hline Age (years) & Frequency $(\mathbf{n})$ & $\begin{array}{l}\text { Percentage } \\
(\%)\end{array}$ \\
\hline $21-30$ & 9 & 18.0 \\
\hline
\end{tabular}


Prediction of Grade of Urothelial Carcinoma of Urinary Bladder from the Size and Number of Tumors at First Presentation

\begin{tabular}{|l|l|l|}
\hline $31-40$ & 8 & 16.0 \\
\hline $41-50$ & 7 & 14.0 \\
\hline $51-60$ & 12 & 24.0 \\
\hline$>60$ & 14 & 28.0 \\
\hline Mean \pm SD & $52.04 \pm 18.37$ & \\
\hline
\end{tabular}

Males $(56.0 \%)$ were predominant than females (44.0\%). Male to female ratio was 1.27:1.

Table2. Distribution of the study subjects according to gender $(N=50)$

\begin{tabular}{|l|l|l|}
\hline Gender & Frequency $(\mathbf{n})$ & $\begin{array}{l}\text { Percentage } \\
(\boldsymbol{\%})\end{array}$ \\
\hline Male & 28 & 56.0 \\
\hline Female & 22 & 44.0 \\
\hline
\end{tabular}

Most of the patients had hematuria (68.0\%).

Table3. Presenting complain of the study subjects $(N=50)$

\begin{tabular}{|l|l|l|}
\hline Hematuria & Frequency $(\mathrm{n})$ & Percentage $(\%)$ \\
\hline Yes & 34 & 68.0 \\
\hline No & 16 & 32.0 \\
\hline
\end{tabular}

Fifteen $(30.0 \%)$ patients had smoking habit.

Table4. Smoking habit of the study subjects $(N=50)$

\begin{tabular}{|l|l|l|}
\hline Smoking & Frequency $(\mathrm{n})$ & Percentage $(\%)$ \\
\hline Yes & 15 & 30.0 \\
\hline No & 35 & 70.0 \\
\hline
\end{tabular}

Regarding urine R/M/E, mean PUS cell was 9.86 \pm 4.81 and mean RBC was $28.02 \pm 11.35$.

Table 5: Urine $R / M / E$ findings of the study subjects $(N=50)$

\begin{tabular}{|l|l|l|}
\hline & Frequency $(\mathrm{n})$ & Percentage $(\%)$ \\
\hline Pus cell & $9.86 \pm 4.81$ & $2.00-20.00$ \\
\hline RBC & $28.02 \pm 11.35$ & $5.00-45.00$ \\
\hline
\end{tabular}

Regarding tumor information, mean number of tumor was $1.28 \pm 0.64$ within the range of $1-3$ and mean tumor size was $3.54 \pm 1.47 \mathrm{~cm}$ within the range of $1-7 \mathrm{~cm}$.

Table 6: Number and size of the tumors of the study subjects $(N=50)$

\begin{tabular}{|l|l|l|}
\hline & Frequency $(\mathrm{n})$ & Percentage $(\%)$ \\
\hline Number of tumor & $1.28 \pm 0.64$ & $1-3$ \\
\hline Size of the tumor & $3.54 \pm 1.47$ & $1.00-7.00$ \\
\hline
\end{tabular}

Figure 1 shows ROC curves of tumor number and tumor size in predicting tumor grading. According to ROC curves tumor size showed better Area Under Curve (AUC) than tumor number in predicting tumor grading.

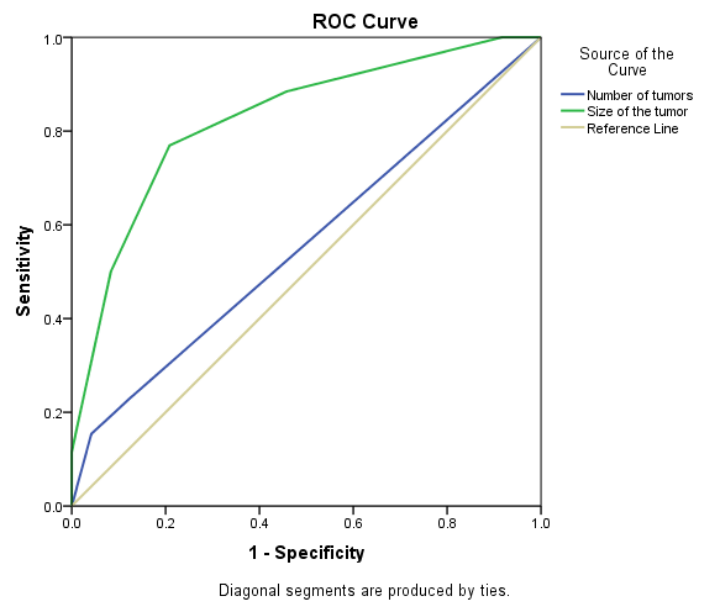

Figure1. ROC curve of tumor number and tumor size in prediction of tumor grading.

Table 7 shows AUC of tumor number and tumor size in prediction of tumor grading. Area under curve (AUC) of tumor number and tumor size was 0.558 and 0.827 respectively in prediction of tumor grading.

Table7. AUC of tumor number and tumor size in prediction of tumor grading

\begin{tabular}{|c|c|c|c|c|c|}
\hline \multirow[t]{2}{*}{ Variable } & \multirow[t]{2}{*}{ Area } & \multirow[t]{2}{*}{ SE } & \multirow{2}{*}{$\begin{array}{l}\text { p- } \\
\text { value }\end{array}$} & \multicolumn{2}{|c|}{$95 \%$ CI } \\
\hline & & & & $\begin{array}{l}\text { Lower } \\
\text { Bound }\end{array}$ & $\begin{array}{l}\text { Upper } \\
\text { Bound }\end{array}$ \\
\hline $\begin{array}{l}\text { Number } \\
\text { of tumor }\end{array}$ & 0.558 & 0.082 & 0.485 & 0.398 & 0.718 \\
\hline $\begin{array}{|ll|}\begin{array}{l}\text { Size } \\
\text { tumor }\end{array} & \text { of } \\
\end{array}$ & 0.827 & 0.059 & 0.000 & 0.711 & 0.943 \\
\hline
\end{tabular}

According to Youden index best cut off value of tumer number is 3 in predicting tumor grading

Table8. Youden index of tumor number in prediction of tumor grading $(N=50)$

\begin{tabular}{|l|l|l|l|}
\hline $\begin{array}{l}\text { Number of } \\
\text { tumor }\end{array}$ & Sensitivity & Specificity & Youden Index \\
\hline 1 & 1.000 & 0.000 & 0.000 \\
\hline 2 & 0.231 & 0.875 & 0.106 \\
\hline 3 & 0.154 & 0.958 & 0.112 \\
\hline 4 & 0.000 & 1.000 & 0.000 \\
\hline
\end{tabular}

According to Youden index best cut off value of tumor size is $3.50 \mathrm{~cm}$ in predicting tumor grading

Table9. Youden index of tumor size in prediction of tumor grading $(N=50)$

\begin{tabular}{|l|l|l|l|}
\hline $\begin{array}{l}\text { Tumor } \\
\text { size }\end{array}$ & Sensitivity & Specificity & Youden Index \\
\hline 1.50 & 1.000 & 0.083 & 0.083 \\
\hline 2.50 & 0.885 & 0.542 & 0.426 \\
\hline 3.50 & 0.769 & 0.792 & 0.561 \\
\hline 4.50 & 0.500 & 0.917 & 0.417 \\
\hline 5.50 & 0.115 & 1.000 & 0.115 \\
\hline 6.50 & 0.077 & 1.000 & 0.077 \\
\hline 8.00 & 0.000 & 1.000 & 0.000 \\
\hline
\end{tabular}


Prediction of Grade of Urothelial Carcinoma of Urinary Bladder from the Size and Number of Tumors at First Presentation

Table 10 shows association of tumor grading with tumor number at cut off value 3 . There was no significant association of tumor grading with tumor number.

Table10. Association of tumor grading with tumor number at cut off value $3(N=50)$

\begin{tabular}{|c|c|c|c|c|}
\hline \multirow{2}{*}{\begin{tabular}{|l} 
Number of \\
tumors
\end{tabular}} & \multicolumn{2}{|c|}{ Grading of tumor } & \multirow[t]{2}{*}{ Total } & \multirow{2}{*}{\begin{tabular}{|l} 
p- \\
valu \\
e
\end{tabular}} \\
\hline & High grade & Low grade & & \\
\hline$\geq 3$ & $4(15.4)$ & $1(4.2)$ & $5(10.0)$ & 0.351 \\
\hline$<3$ & $22(84.6)$ & $23(95.8)$ & $45(90.0)$ & \\
\hline Total & $26(100.0)$ & $24(100.0)$ & $50(100.0)$ & \\
\hline
\end{tabular}

Fisher's Exact test was done to measure the level of significance

Table 11 shows association of tumor grade with tumor size at cut off value 3.5. High grade tumor was significantly higher among the study subjects with tumor size $>3.5 \mathrm{~cm}$.

Table11. Association of tumor grade with tumor size at cut off value $3.5(N=50)$

\begin{tabular}{|c|c|c|c|c|}
\hline \multirow{2}{*}{\begin{tabular}{|l|} 
Size \\
tumor \\
$(\mathrm{cm})$
\end{tabular}} & \multicolumn{2}{|c|}{\begin{tabular}{l|l} 
of & Grade of tumor
\end{tabular}} & \multirow[t]{2}{*}{ Total } & \multirow{2}{*}{$\begin{array}{l}\text { p- } \\
\text { value }\end{array}$} \\
\hline & \begin{tabular}{|l|} 
High \\
grade
\end{tabular} & $\begin{array}{l}\text { Low } \\
\text { grade }\end{array}$ & & \\
\hline$>3.5$ & $20(76.9)$ & $5(20.8)$ & $25(50.0)$ & $\begin{array}{l}<0.00 \\
1\end{array}$ \\
\hline$\leq 3.5$ & $6(23.1)$ & $19(79.2)$ & $25(50.0)$ & \\
\hline Total & $26(100.0)$ & $\begin{array}{l}24 \\
(100.0)\end{array}$ & $\begin{array}{l}50 \\
(100.0)\end{array}$ & \\
\hline
\end{tabular}

Chi-Square test was done to measure the level of significance

Table 12 shows sensitivity, specificity, PPV and NPV of tumor number and tumor size in prediction of tumor grading. Sensitivity, specificity, PPV, NPV and accuracy of tumor number (at cut of value 3) was $15.4 \%, 95.8 \%$, $80.0 \%, 51.1 \%$ and $54.0 \%$ respectively. Sensitivity, specificity, PPV, NPV and accuracy of tumor size (at cut of value $3.5 \mathrm{~cm}$ ) was $90.5 \%$, $76.3 \%, 80.9 \%, 87.9 \%$ and $83.7 \%$ respectively. Overall Sensitivity, specificity, PPV, NPV and accuracy of tumor size was better than tumor number in prediction of tumor grading.

Table12. Sensitivity, specificity, accuracy, $P P V$ and $N P V$ of tumor number and tumor size in prediction of tumor grading $(N=50)$

\begin{tabular}{|l|l|l|l|l|l|l|}
\hline $\begin{array}{l}\text { Tumo } \\
\text { r }\end{array}$ & $\begin{array}{l}\text { Cut } \\
\text { off } \\
\text { valu } \\
\text { e }\end{array}$ & $\begin{array}{l}\text { Sensitivi } \\
\text { ty }\end{array}$ & $\begin{array}{l}\text { Specifici } \\
\text { ty }\end{array}$ & $\begin{array}{l}\text { PP } \\
\text { V }\end{array}$ & $\begin{array}{l}\text { NP } \\
\text { V }\end{array}$ & $\begin{array}{l}\text { Accura } \\
\text { cy }\end{array}$ \\
\hline $\begin{array}{l}\text { Numb } \\
\text { er }\end{array}$ & 3 & 15.4 & 95.8 & $\begin{array}{l}80 . \\
0\end{array}$ & 51.1 & 54.0 \\
\hline
\end{tabular}

\begin{tabular}{|l|l|l|l|l|l|l|}
\hline Size & 3.5 & 76.9 & 79.2 & $\begin{array}{l}80 . \\
0\end{array}$ & 76.0 & 78.0 \\
\hline
\end{tabular}

\section{DISCUSSION}

Bladder cancer is the second most common cancer of the genito-urinary tract. Urothelial carcinoma can be High grade and low grade according to WHO criteria. Low grade disease usually is not life threatening though frequently recurrent and less frequently involves detrusor muscle and deeper tissues. But high-grade disease is a potentially fatal disease which frequently invades detrusor muscle and beyond. Timely cystectomy can save lives but that requires early diagnosis and prompt treatment. The confirmatory test for grade of the disease is histopathological examination after transurethral resection. But if the grade of the tumor can be predicted at the time of presentation from size and number of tumors seen by ultrasonographic imaging, clinician can counsel the patient beforehand and also arrange rapid treatment to save life. Mean age of the study subjects was $52.04 \pm 18.37$ years within the range of 22-95 years. Males $(56.0 \%)$ were predominant than females $(44.0 \%)$. Male to female ratio was 1.27:1. Mean age was $66.1 \pm 14.3$ years and male to female ratio was 4.19:1 in the study of Shapur et al. [5]. Most of the patients had hematuria (68.0\%). Fifteen (30.0\%) patients had smoking habit. Regarding urine R/M/E, mean PUS cell was $9.86 \pm 4.81$ and mean $\mathrm{RBC}$ was $28.02 \pm$ 11.35 in this study. The use of ultrasonography for the diagnosis of bladder cancer is well established since the early 1980s [22, 23]. It is a very sensitive modality for tumors greater than $0.5 \mathrm{~cm}$ with almost $100 \%$ detection rate independent of their location [24]. Regarding tumor information, mean number of tumor was $1.28 \pm 0.64$ (1-3) and mean tumor size was 3.54 $\pm 1.47 \mathrm{~cm}(1-7)$ in this study. Mean number of tumor was $1.16 \pm 0.5$ and mean size of tumor was $2.5 \pm 1.4$ in the study of Shapur et al. [5]. In this study, high grade $26(52.0 \%)$ tumor was and low grade tumor was $24(48.0 \%)$. In the study of Shapur et al. [5], high grade tumor was 169 $(39.2 \%)$ and low grade tumor was (60.8\%). There was no significant association of tumor grading with number of tumor in this study. The number of tumors on ultrasound was not related to the risk of high-grade tumors [5]. High grade tumor was significantly higher among the study subjects with tumor size $>3.5 \mathrm{~cm}$. The risk of a high-grade tumor was 14, 29, 43.3, 55.7 and $69.4 \%$ at the tumor size $0.5-1.5,1.6-2,2.1-2.5$, 2.6-3 and $13.1 \mathrm{~cm}$, respectively [5]. Area under 
curve (AUC) of tumor number and tumor size was 0.558 and 0.827 respectively in prediction of tumor grading. Sensitivity, specificity, PPV, NPV and accuracy of tumor number (at cut of value 3) was $15.4 \%, 95.8 \%, 80.0 \%, 51.1 \%$ and $54.0 \%$ respectively. Sensitivity, specificity, PPV, NPV and accuracy of tumor size (at cut of value $3.5 \mathrm{~cm}$ ) was $90.5 \%, 76.3 \%, 80.9 \%, 87.9 \%$ and $83.7 \%$ respectively. Overall Sensitivity, specificity, PPV, NPV and accuracy of tumor size was better than tumor number in prediction of tumor grading.

\section{CONCLUSION}

According to this study finding, it can be concluded that the grade of newly diagnosed bladder tumors can be predicted with high accuracy using tumor size but number of tumor cannot be used as predictor of high grade tumor.

\section{REFERENCES}

[1] Badrinath, R., Konety and Peter, R., 2013. Carrol: Urothelial carcinoma in Smith \&Tanagho's General Urologyedited by Tom F. Lue, Jack W. McAninch (Eds), $18^{\text {th }}$ edition, McGrawhil. p. 310

[2] Parkin, D.M., 2008. The global burden of urinary bladder cancer. Scandinavian journal of urology and nephrology, 42(sup218), pp.12-20.

[3] Jemal, A., Center, M.M., DeSantis, C. and Ward, E.M., 2010. Global patterns of cancer incidence and mortality rates and trends. Cancer Epidemiology and Prevention Biomarkers, 19(8), pp.1893-1907.

[4] Babjuk, M., Oosterlinck, W., Sylvester, R., Kaasinen, E., Böhle, A., Palou-Redorta, J., et al. 2011. EAU guidelines on non-muscleinvasive urothelial carcinoma of the bladder, the 2011 update. European urology, 59(6), pp.997-1008.

[5] Shapur, N., Pode, D., Katz, R., Shapiro, A., Yutkin, V., Pizov, G., et al. 2011. Predicting the risk of high-grade bladder cancer using noninvasive data. Urologia internationalis, 87(3), pp.319-324.

[6] Miyake, M., Gotoh, D., Shimada, K., Tatsumi, Y., Nakai, Y., Anai, S., et al. 2015. Exploration of risk factors predicting outcomes for primary T1 high-grade bladder cancer and validation of the Spanish Urological Club for Oncological Treatment scoring model: long-term follow-up experience at a single institute.
International Journal of Urology, 22(6), pp.541-547.

[7] Mostofi, F.K., Sobin, L.H., Torloni, H. and World Health Organization, 1973. Histological typing of urinary bladder tumours. World Health Organization.

[8] Sauter, G., Algaba, F., Amin, M., Busch, C., Cheville, J., Gasser, T., Grignon, D.J., Hofstadter, F., Lopez-Beltran, A. and Epstein, J.I., 2004. Tumours of the urinary system: non-invasive urothelial neoplasias.

[9] Brausi, M.A., 2013. Primary prevention and early detection of bladder cancer: two main goals for urologists. European urology, 63(2), p.242.

[10] Ferlay, J., Randi, G., Bosetti, C., Levi, F., Negri, E., Boyle, P. and La Vecchia, C., 2008. Declining mortality from bladder cancer in Europe. BJU international, 101(1), pp.11-19.

[11] Ferlay, J.S.H.R., Shin, H.R., Bray, F., Forman, D., Mathers, C. and Parkin, D.M., 2010. Cancer incidence and mortality worldwide. Lyon: International Agency for Research on Cancer.

[12] Colombel, M., Soloway, M., Akaza, H., Böhle, A., Palou, J., Buckley, R., Lamm, D., Brausi, M., Witjes, J.A. and Persad, R., 2008. Epidemiology, staging, grading, and risk stratification of bladder cancer. european urology supplements, 7(10), pp.618-626.

[13] Bosetti, C., Bertuccio, P., Chatenoud, L., Negri, E., La Vecchia, C. and Levi, F., 2011. Trends in mortality from urologic cancers in Europe, 1970-2008. European urology, 60(1), pp.1-15.

[14] Burger, M., Catto, J.W., Dalbagni, G., Grossman, H.B., Herr, H., Karakiewicz, P., Kassouf, W., Kiemeney, L.A., La Vecchia, C., Shariat, S. and Lotan, Y., 2013. Epidemiology and risk factors of urothelial bladder cancer. European urology, 63(2), pp.234-241.

[15] Freedman, N.D., Silverman, D.T., Hollenbeck, A.R., Schatzkin, A. and Abnet, C.C., 2011. Association between smoking and risk of bladder cancer among men and women. Jama, 306(7), pp.737-745.

[16] Kirkali, Z., Chan, T., Manoharan, M., Algaba, F., Busch, C., Cheng, L., Kiemeney, L., Kriegmair, M., Montironi, R., Murphy, W.M. and Sesterhenn, I.A., 
2005. Bladder cancer: epidemiology, staging and grading, and diagnosis. Urology, 66(6), pp.4-34.

[17] Samanic, C.M., Kogevinas, M., Silverman, D.T., Tardon, A., Serra, C., Malats, N., Real, F.X., Carrato, A., Garcia-Closas, R., Sala, M. and Lloreta, J., 2008. Occupation and bladder cancer in a hospital-based casecontrol study in Spain. Occupational and environmental medicine, 65(5), pp.347-353.

[18] Rushton, L., Bagga, S., Bevan, R., Brown, T.P., Cherrie, J.W., Holmes, P., et al. 2010. Occupation and cancer in Britain. British journal of cancer, 102(9), pp.1428-1437.

[19] Koutros, S., Silverman, D.T., Baris, D., Zahm, S.H., Morton, L.M., et al., 2011. Hair dye use and risk of bladder cancer in the New England bladder cancer study. International Journal of Cancer, 129(12), pp.2894-2904.

[20] Ros, M.M., Gago-Dominguez, M., Aben, K.K., Bueno-de-Mesquita, H.B., Kampman, E., Vermeulen, S.H. et al. 2012. Personal hair dye use and the risk of bladder cancer: a case-control study from The Netherlands. Cancer Causes \& Control, 23(7), pp.11391148.

[21] Rafnar, T., Vermeulen, S.H., Sulem, P., Thorleifsson, G., Aben, K.K., Witjes, J.A., et al. 2011. European genome-wide association study identifies SLC14A1 as a new urinary bladder cancer susceptibility gene. Human molecular genetics, 20(21), pp.4268-4281.

[22] Itzchak, Y., Singer, D. and Fischelovitch, Y., 1981. Ultrasonographic assessment of bladder tumors. I. Tumor detection. The Journal of urology, 126(1), pp.31-33.

[23] Dibb, M.J., Noble, D.J., Peh, W.C., Lam, C.H., Yip, K.H., Li, J.H. and Tam, P.C., 2001. Ultrasonographic analysis of bladder tumors. Clinical imaging, 25(6), pp.416420.

[24] Ozden, E., Turgut, A.T., Turkolmez, K., Resorlu, B. and Safak, M., 2007. Effect of bladder carcinoma location on detection rates by ultrasonography and computed tomography. Urology, 69(5), pp.889-892.

Citation: Mahbubul Islam Khandoker, Md. Shamim Hossain, A.S.M Shafiul Azam, Muhammad Serajul Islam, Akter Kamal Perveg, Mohammad Abdus Salam, A. K. Al-Miraj. Prediction of Grade of Urothelial Carcinoma of Urinary Bladder from the Size and Number of Tumors at First Presentation. ARC Journal of Urology. 2021; 6(1):1-7. DOI: https://doi.org/10.20431/2456-060X.060101.

Copyright: () 2021 Authors. This is an open-access article distributed under the terms of the Creative Commons Attribution License, which permits unrestricted use, distribution, and reproduction in any medium, provided the original author and source are credited. 